\title{
A FORMAÇÃO EM SAÚDE À LUZ DO PROJETO PEDAGÓGICO E DAS DIRETRIZES CURRICULARES DA EDUCAÇÃO FÍSICA
}

\author{
HEALTH TRAINING UNDER PHYSICAL EDUCATION'S PEDAGOGICAL \\ PROJECT AND CURRICULAR GUIDELINES
}

LA CAPACITACIÓN EN SALUD A LA LUZ DEL PROYECTO PEDAGÓGICO Y DE LAS DIRECTRICES CURRICULARES PARA LA EDUCACIÓN FÍSICA

\section{Maria Luci Esteves Santiago*, José Ivo Santos Pedrosa*, Alex Soares Marreiros Ferraz ${ }^{* \star}$}

\section{Palavras-chave} Educação Física e treinamento.

Ensino.

Sistema Único de Saúde.

Keywords Physical Education and Training. Education. Unified Health System.

\section{Palabras clave} Educación y Entrenamiento Físico.

Enseñanza. Sistema Único de Salud.
Resumo: A Educação Física tem, tradicionalmente, se pautado em um conceito restrito de saúde. $O$ objetivo deste trabalho é analisar no Projeto Pedagógico do Curso de Educação Física, bem como nas Diretrizes Curriculares Nacionais da área, o processo formativo ligado à atuação em saúde e ao SUS, por meio de pesquisa documental. Os pressupostos teóricos hegemônicos do curso e da área apresentam-se distantes dos princípios do SUS, reafirmando o alargamento entre as políticas de formação em Educação Física e as da Saúde Coletiva.

Abstract: Traditionally, Physical Education has been based on a limited concept of health. Through document research, this work analyzes, in the Pedagogical Project of the Physical Education Course and the National Curriculum Guidelines for the area, the training process linked to working in health and at Brazil's Unified Health System (SUS). The hegemonic theoretical assumptions of the course and the area are detached from SUS principles, underscoring the distance between educational policies in Physical Education and those in the public health field.

Resumen: La Educación Física, tradicionalmente, se ha basado en un concepto limitado de salud. El objetivo de este trabajo es analizar el Proyecto Pedagógico del Curso de Educación Física, así como las Directrices Curriculares Nacionales de ese campo, el proceso de formación relacionado al desempeño en salud y al Sistema Único de Salud, SUS, mediante investigación documental. Las hipótesis teóricas hegemónicas del curso y del área se muestran distantes de los principios del SUS, reafirmando la brecha entre las políticas de formación en Educación Física y las de la salud colectiva.
* Universidade Estadual do Piauí. Teresina, PI, Brasil. E-mail: mles@ hotmail.com; jivopedrosa@gmail.com

** Universidade Federal do Ceará Fortaleza, CE, Brasil.

E-mail: ferrazalex@hotmail.com

Recebido em: 22-08-2015 Aprovado em: 08-12-2015 (c) (i) (2) Licence 


\section{INTRODUÇÃO}

A instituição dos Núcleos de Apoio à Saúde da Família (NASF) como campo de atuação da Educação Física (EF) no Sistema Único de Saúde (SUS) brasileiro traz novos elementos à pauta de discussões sobre as fragilidades da formação do profissional de EF para a atuação na Saúde Coletiva (FALCl; BELISÁRIO, 2013).

A formação em EF tem sido guiada, historicamente, por concepções médico-higienistas, biologicistas, de valoração das habilidades físico-esportivas; ou, mais especificamente, como aponta Luz (2007, p.11), por um "[...] conjunto de saberes e práticas tradicionais ligadas ao treinamento do corpo e/ou seu adestramento", fato ainda hegemônico nos dias atuais, apesar das contribuições sócio-históricas e pedagógicas construídas, principalmente na década de 1980, que ampliaram as percepções, discussões e ações da formação nesta área (BRUGNEROTTO, 2008).

Sobre a importância da formação, Loch et al. (2011) consideram que ela é um dos mais importantes fatores a serem considerados na busca por uma melhor atuação no contexto da Saúde Coletiva, visto que, ao ser considerada como profissão da saúde, a EF necessita ter sua formação alinhada ao SUS, e este deve pautar/ordenar a formação dos recursos humanos na área (BRASIL, 1988).

Buscando ajustar a formação em saúde e aproximá-la das necessidades do SUS, os Ministérios da Saúde e da Educação vêm, paulatinamente, implementando e apoiando ações de formação acadêmica, entre as quais se destacam a sanção das Diretrizes Curriculares Nacionais (DCN) dos cursos de graduação em saúde, o Programa Nacional de Reorientação da Formação Profissional em Saúde (Pró-Saúde), o Programa de Educação pelo Trabalho para a Saúde (PET-Saúde) e os Estágios de Vivência no SUS (VER-SUS). Tais ações geraram alterações nas matrizes curriculares dos cursos da área de saúde de algumas Instituições de Ensino Superior (IES), contudo ainda não conseguiram a abrangência pretendida (ANJOS; DUARTE, 2009, BRUGNEROTTO, 2008).

Considerando que a formação inicial em nível de graduação é campo privilegiado para o desenvolvimento de capacidades, habilidades e atitudes relacionadas ao futuro exercício da profissão (LIBÂNEO, 2004), o presente trabalho' busca analisar no Projeto Pedagógico do Curso (PPC) de Educação Física, bem como nas DCN dessa área, o processo formativo ligado à atuação em saúde e ao SUS.

\section{PERCURSO TEÓRICO-METODOLÓGICO}

De natureza descritivo-exploratória, o estudo utiliza a análise documental (GIL, 2009, TRIVIÑOS, 1987), apoiado ainda em uma abordagem qualitativa (MINAYO, 2009). Utilizou-se como corpus o PPC de Educação Física da UFPI (UNIVERSIDADE FEDERAL DO PIAUÍ, 2009) e as Diretrizes Curriculares Nacionais para formação em Educação Física - DCN (BRASIL, 2004), por esses documentos comporem ferramentas essenciais para orientar o processo

10 texto que se segue é um recorte do trabalho de dissertação de mestrado do Programa Ciências e Saúde da UFPI, da linha de pesquisa Ensino na Saúde que vem desenvolvendo estudo matricial sobre a formação dos profissionais na área da saúde (UNIVERSIDADE FEDERAL DO PIAUÍ, 2010). Como também consideramos um recorte na construção de competências para a atuação em saúde apenas a discussão da formação acadêmica, que mesmo podendo repercutir na área específica e nos profissionais de saúde, deve estar inserida em um contexto mais amplo de discussões e conquistas sociais relacionadas ao direito à saúde. 
formativo em EF na citada instituição. Os documentos foram obtidos, respectivamente, na coordenação do curso de EF da UFPI e no portal do Ministério da Educação, sendo estes lidos, estudados e analisados entre maio e setembro de 2014.

Dos resultados obtidos foram construídos quadros, enquanto matrizes conceituais, com o objetivo de sintetizar e organizar a análise, contemplando cinco categorias (LAMPERT, 2002): enfoque teórico, abordagem pedagógica, cenários de prática, capacitação docente, mercado de trabalho e serviços de saúde. Diante das limitações estruturais do formato artigo, optamos por apresentar um recorte desta última categoria, analisado em conjunto com o plano de ensino das disciplinas do currículo do curso de EF/UFPI que se aproximavam mais diretamente ao tema saúde.

Essas disciplinas foram selecionadas pela presença de palavras-chave no nome, ementa ou bibliografia da disciplina, sendo saúde o termo principal, associado a termos afins como qualidade de vida, bem-estar, sadio, saudável, desenvolvimento biopsicossocial, empoderamento, autonomia, integralidade e contexto social. Essa etapa foi embasada pelas leituras exploratória e seletiva apresentadas por Gil (2009), Marconi e Lakatos (2010), Cervo; Bervian e Silva (2010) e objetivaram extrair uma visão geral do material, entender a organização interna dos documentos e selecionar as informações mais relevantes relacionadas com o problema proposto.

Para a análise dos dados utilizaram-se as técnicas de leitura analítica e interpretativa, buscando palavras-chave que sintetizassem e favorecessem a hierarquização das ideias centrais e secundárias do texto. A teoria da Análise de Conteúdo (BARDIN, 2011) também foi utilizada como base para análise, pois "há uma considerável associação da pesquisa documental com Análise de Conteúdo pelo interesse de extrair um sentido, uma representação de um pensamento ou ideologia subjacente" (BELTRÃO; NOGUEIRA, 2011, p.1).

Os resultados e discussões foram sistematizados em mapas conceituais, que refletiram a organização do entendimento sobre o objeto em estudo, conforme preconiza Lima (2004). Para tanto utilizou-se o software Go Diagram for WinForms version 2.6.2 (2007) - ferramenta State Charter - pelo seu fácil manuseio na edição de diagramas interativos. As categorias principais pensadas para a sistematização do artigo foram firmadas no topo do mapa conceitual e demarcadas em cinza escuro, sendo suas subcategorias demarcadas com tom mais claro, sendo apresentadas a seguir.

\section{INFLUÊNCIAS HISTÓRICAS DA FORMAÇÃO EM SAÚDE NA EDUCAÇÃO FíSICA}

Historicamente a EF teve sua relação com a saúde ligada a ideias militaristas e higienistas, de preparação e manutenção do corpo forte e saudável, perspectiva que determinou uma supervalorização dos aspectos biológicos no pensar o movimento humano (CARVALHO, 2005). Nessa perspectiva, o paradigma biomédico exerce grande influência sobre o fazer e a formação em EF num modelo diagnóstico-prescritivo (LUZ, 2007), afirmando uma visão restrita de saúde que desfavorece as práticas cuidadoras longitudinais relacionadas ao processo saúde-doença-cuidado.

Esse modus operandi, característico da prática médica, colonizou o processo de trabalho de outras profissões da área da saúde, que, na busca de legitimação como campo específico de saber científico, quase sempre se rendem à força hegemônica do paradigma 
biomédico (CECCIM; BILIBIO, 2007). Tais influências fizeram e ainda fazem vigorar no ambiente formativo dos cursos da área da saúde uma visão predominantemente biologicista do processo saúde-doença-cuidado, determinando uma organização curricular centrada na transmissão de conhecimento hierarquizado e verticalizado (FRAGA; CARVALHO; GOMES, 2012).

Partindo desse pressuposto, o indivíduo é restrito a um corpo físico, com problemas apenas percebidos pelos saberes especializados, produzindo uma racionalização do sujeito e do profissional, limitando o fazer em saúde a um rito que obstaculiza uma ação de sujeitos na relação de cuidado (ROCHA; CENTURIÃO, 2007). Sobre essa ritualização, Palma (2001) salienta que a EF tem direcionado a formação e atuação da área basicamente a aspectos técnicos, ao saber-fazer de forma mecânica, repetitiva e pouco reflexiva, ficando os demais saberes sem espaço na formação. Isso pode ser percebido pelo fato de que ainda se evidencia, nos cursos de EF, uma racionalidade técnica na forma como os currículos estão estruturados, bem como no fazer pedagógico dos docentes (BARBOSA RINALDI, 2008).

A Figura 1 sintetiza tais relações, subjacentes à formação em EF identificadas claramente no PPC e fortemente apoiadas pelas DCN. São ilustrativas do avanço nos estudos e conhecimentos epidemiológicos desenvolvidos e consolidados principalmente na década de 1980, que trouxeram ou retomaram perspectiva de formação para atuação profissional pautada predominantemente no paradigma da aptidão física e promoção da saúde (BRACHT, 1999).

Figura 1 - Mapa conceitual dos resultados e discussões, referentes à categoria Influências Históricas da Formação em Saúde na Educação Física, evidente nos documentos normativos analisados.

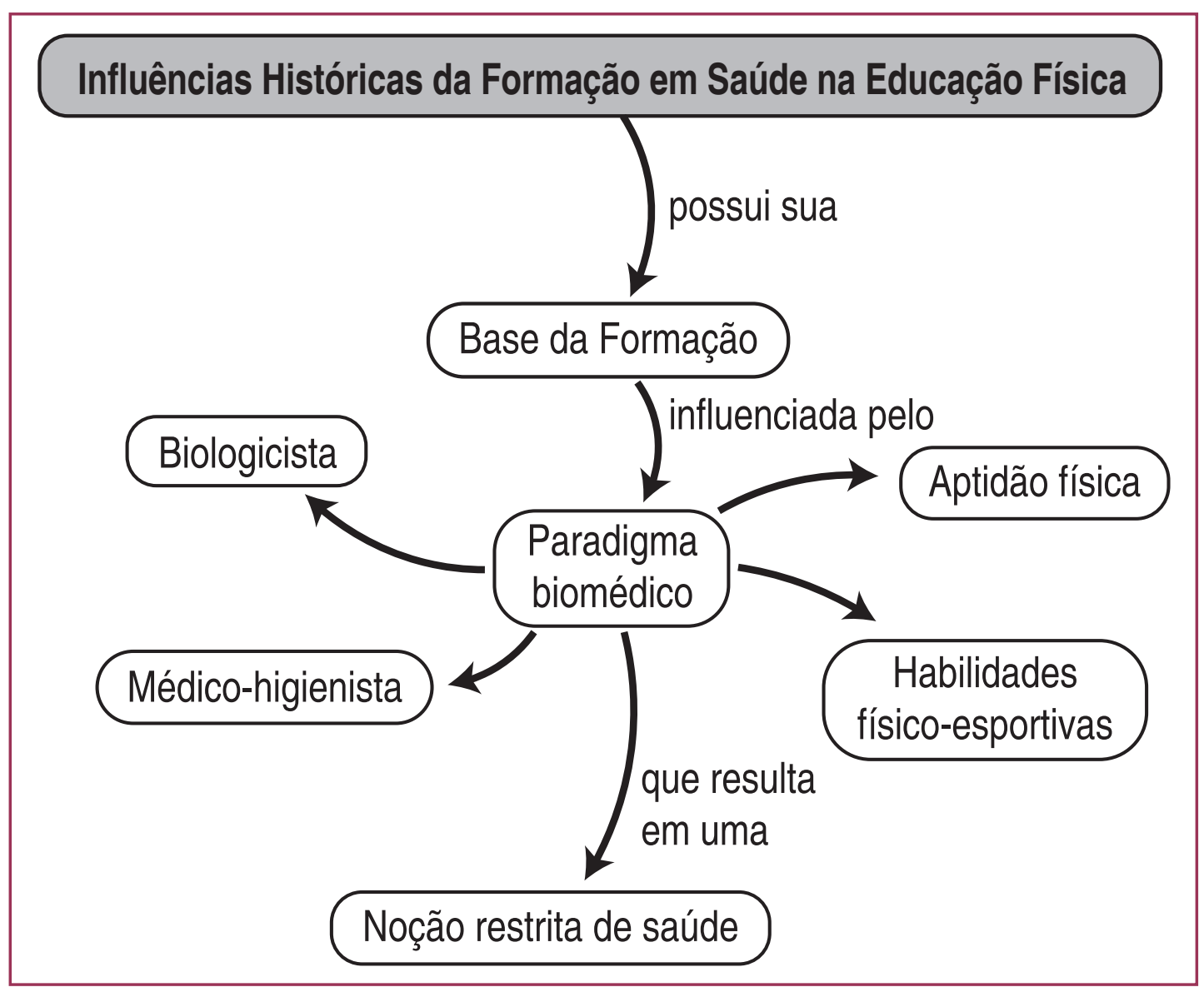


A elaboração das DCN foi permeada por intensos debates, especialmente entre 0 Conselho Federal de Educação Física (CONFEF) e instituições/colegiados científicos de professores especialmente sobre o novo tipo de formação para além da licenciatura, o bacharel em EF (LEMOS et al., 2012). Segundo Taffarel (2012), as DCN vêm ajudando a precarizar a formação em EF, em função de uma divisão que gera fragmentação do conhecimento e lacunas na formação, pela divisão e negação do conhecimento e postos de trabalho. Sobre essa divisão da formação, Pasquim (2010), ao usar a expressão "distúrbio bipolar institucional", busca caracterizar que a fragmentação da formação em dois polos antagônicos, do licenciado e sua visão restrita à escola e do bacharel e sua visão restrita ao treinamento, desfavorece uma prática integral na EF.

O crescimento do mercado de trabalho não escolar, especialmente ligado ao binômio exercício físico-saúde, representado por clubes, academias e spas, é oriundo da explosão do fitness norte-americano que perpetuou a ideia de que a exercitação corporal gera saúde por si só e do suporte mercadológico que sustenta essa ideia (BRUGNEROTTO, 2008), tendo sido a mais forte justificativa para a separação da formação e gerando um aprofundamento do processo de alienação na formação em EF (TAFFAREL, 2012).

Outro fato histórico reforçou sobremaneira a relação da EF com o paradigma biomédico: seu reconhecimento formal como uma das categorias profissionais da saúde em 1997, por meio da Resolução do CNS (BRASIL, 1997), valorizando ainda mais a formação profissional predominantemente centrada na avaliação do comportamento de risco, em uma intervenção prescritiva e na percepção biomédica do processo saúde-doença (FRAGA; CARVALHO; GOMES, 2012).

Abaixo são apresentados alguns fragmentos dos documentos analisados que embasam tais considerações:

Atuar na proteção e na promoção da saúde e na prevenção de doenças, bem como no tratamento e reabilitação dos problemas de saúde. (UNIVERSIDADE FEDERAL DO PIAUÍ, 2009, p. 19, grifo nosso)

No contexto educacional, aptidão física e a prática de atividades físicas e esportivas devem ser entendidas como necessárias e importantes para todos, principalmente para que se evite que as pessoas se mantenham sedentárias, obesas, com baixos níveis de aptidão física, fatores geradores de doenças. (UNIVERSIDADE FEDERAL DO PIAUÍ, 2009, p. 1, grifo nosso)

Essa lógica da formação centrada no "fazer saúde", focada na doença, favorece uma noção de saúde centrada nos componentes orgânicos, avaliados por suas particularidades corporais e/ou fisiológicas, por sinais e sintomas manifestos, em que os sujeitos, suas relações sociais e estratégias de promoção da saúde são desvalorizados enquanto as relações mercadológicas no fazer saúde são reforçadas (ROCHA; CENTURIÃO, 2007).

Uma formação e uma intervenção centradas nos aspectos biológicos da Saúde vêm sendo confrontadas, por conhecimentos imprescindíveis à construção de melhores níveis de saúde das pessoas, grupos e populações, como a "história, as condições emocionais, sociais, culturais e econômicas, que são parte e construção da saúde e da doença" (ROCHA; CENTURIÃO, 2007, p. 21). 
Nesse sentido, Bagrichevsky (2007, p. 38) considera que é preciso entender que "a apropriação de saberes e práticas curriculares da EF precisa considerar o entorno sociocultural onde as relações humanas se estabelecem", além de ter claro que essa percepção da realidade encontra-se distante das possibilidades oferecidas "pela preparação estritamente centrada em habilidades técnico-instrumentais ultra-especializadas", necessitando-se, pois, de um redirecionamento da formação.

Objetivando essa nova formação, Mello, Moyses e Moyses (2010) defendem a diversificação de cenários pedagógicos, além da inclusão de processos ativos de aprendizagem, nos quais a realidade social com suas profundas iniquidades seja apreendida precocemente. E consideram urgente uma formação que contextualize e potencialize abordagens pedagógicas nas quais estejam presentes a interdisciplinaridade, a integralidade, a humanização e a construção da autonomia dos sujeitos, bases de uma formação alinhada aos preceitos do SUS.

\section{FORMAÇÃO ATUAL EM EDUCAÇÃO FÍSICA PARA A SAÚDE}

Os documentos analisados (DCN e PPC) apontam que competências ligadas à saúde devem ser possibilitadas, indo além de uma abordagem temática, específica e técnica, mas que se associem a uma formação para atuação no SUS, pois se encontram relacionadas à promoção, prevenção e recuperação da saúde, atuando especialmente, como destaca o PPC, no atendimento primário, mas também de forma integrada e contínua com todas as instâncias do sistema de saúde.

Os trechos a seguir corroboram essa premissa e ressaltam as atribuições do futuro profissional de EF em sua atuação no mercado de trabalho, ou com foco, na área de saúde:

Atuar nos diferentes níveis de atendimento à saúde, com ênfase nos atendimentos primários e secundários. (UNIVERSIDADE FEDERAL DO PIAUÍ, 2009, p. 19, grifo nosso)

O profissional de Educação Física deve assegurar que sua prática seja realizada de forma segura, integrada e contínua com as demais instâncias do sistema de saúde. (UNIVERSIDADE FEDERAL DO PIAUÍ, 2009, p. 16, grifo nosso)

Compreender a política de saúde, de educação e de esporte [...]. (UNIVERSIDADE FEDERAL DO PIAUÍ, 2009, p. 19, grifo nosso)

Participar da composição das estruturas consultivas e deliberativas do sistema de educação, esporte e saúde. (UNIVERSIDADE FEDERAL DO PIAUÍ, 2009, p. 20 , grifo nosso)

Diagnosticar os interesses, as expectativas e as necessidades das pessoas [...] de modo a planejar, [...] projetos e programas de atividades físicas, recreativas e esportivas nas perspectivas da prevenção, promoção, proteção e reabilitação da saúde, [...]. (BRASIL, 2004, p. 2, grifo nosso)

Todavia, observam-se, na Figura 2, inúmeros elementos de fragilidade na formação que subsidiariam uma melhor atuação em saúde; destaca-se principalmente a não observação, no PPC, de disciplinas ou espaços para a apropriação deste debate. 
Figura 2 - Mapa conceitual dos resultados e discussões, referentes à categoria Formação atual em Educação Física para a Saúde, evidente nos documentos normativos analisados.

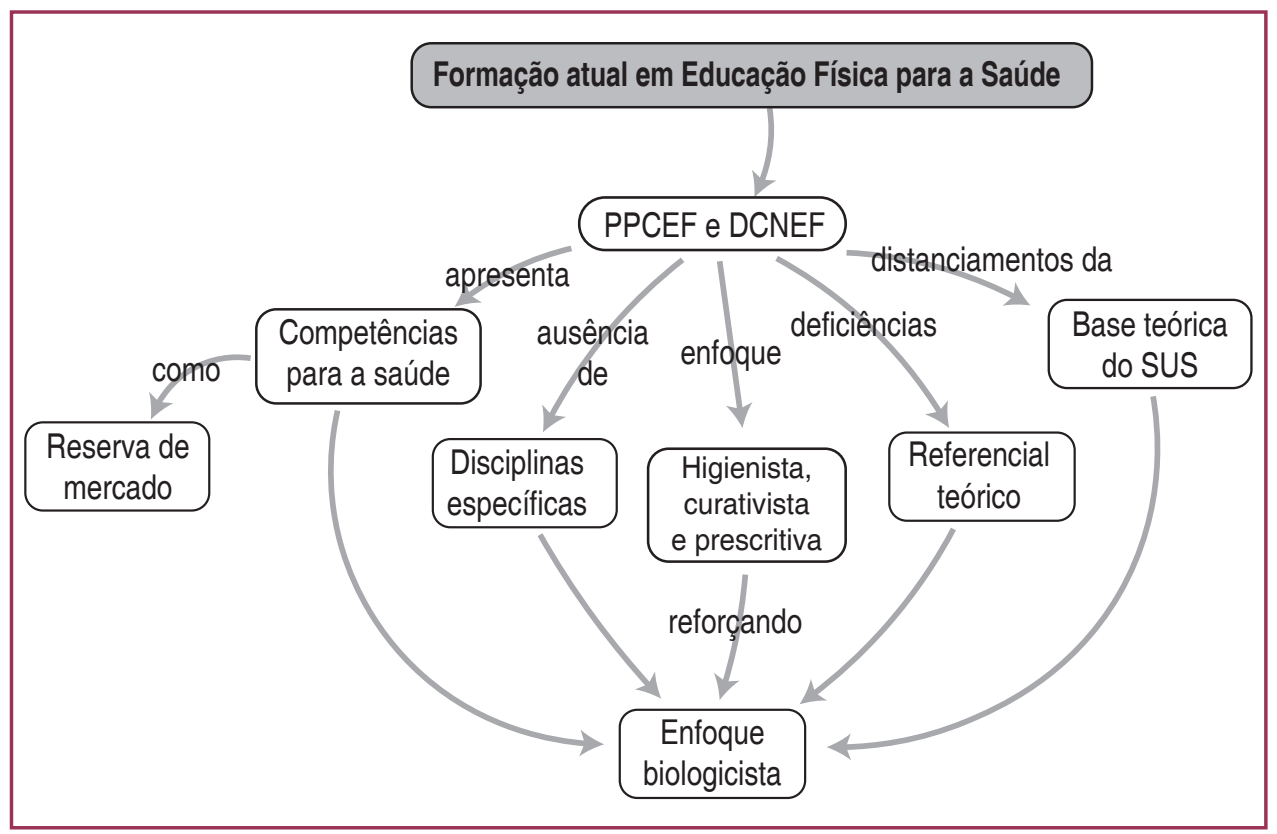

Fonte: Dados dos autores.

O currículo do curso de EF da UFPI é composto por 41 disciplinas (Figura 3) e apresenta uma grande quantidade de disciplinas, de formação específica, ligadas ao esporte (em asterisco), além de uma formação muito ligada aos aspectos biológicos (sublinhadas em negrito). Tais disciplinas reproduzem, ainda sem grandes modificações, o primeiro modelo de currículo da EF, implementado no país no ano de 1939 (AMARAL et al., 2006), o que obstaculiza 0 avanço da formação acadêmica frente aos horizontes e necessidades profissionais, em relação a habilidades, atitudes e conhecimentos, para atuação no campo da Saúde Coletiva.

Figura 3 - Disciplinas do curso de Educação Física da Universidade Federal do Piauí (UFPI), evidente no PPC analisado.

\begin{tabular}{|l|l|l|}
\hline \multicolumn{1}{|c|}{$\begin{array}{c}\text { NÚCLEO DE FORMAÇÃO } \\
\text { PEDAGÓGICA }\end{array}$} & \multicolumn{1}{|c|}{$\begin{array}{c}\text { NÚCLEO DE FORMAÇÃO ESPECÍFICA - } \\
\text { PARTE I }\end{array}$} & \multicolumn{1}{c|}{$\begin{array}{c}\text { NÚCLEO DE FORMAÇÃO } \\
\text { ESPECÍFICA - PARTE II }\end{array}$} \\
\hline Sociologia da Educação & Anatomia da EF & * Introdução ao Ensino de Ginástica \\
\hline Filosofia da Educação & Bioestatística & * Recreação e Lazer \\
\hline Psicologia da Educação & Higiene, Saúde e Meio Ambiente & * Atletismo I \\
\hline $\begin{array}{l}\text { Legislação e Organização da } \\
\text { Educação Básica }\end{array}$ & Introdução à Metodologia Científica & * Natação I \\
\hline Didática Geral & Bioquímica para EF & * Voleibol I \\
\hline História da Educação & Fisiologia para EF & * Basquetebol I \\
\hline Avaliação da Aprendizagem & Primeiros Socorros em EF & * Handebol I \\
\hline Metodologia do Ensino da EF & Biomecânica & * Futebol I \\
\hline Seminário de Iniciação ao Curso & * Administração, Gestão e Marketing Esportivo & * Futsal \\
\hline \multirow{2}{*}{$\begin{array}{l}\text { Linguagem Brasileira de Sinais - } \\
\text { LIBRAS }\end{array}$} & * Teoria e Prática do Treinamento Desportivo & * Dança \\
\hline \multirow{3}{*}{} & Cineantropometria & * Lutas em EF \\
\cline { 2 - 4 } & Metodologia da Pesquisa em EF & * EF Adaptada \\
\cline { 2 - 4 } & Fundamentos Históricos, Teoria e Ética da EF & Seminário de Pesquisa \\
\cline { 2 - 4 } & Desenvolvimento e Aprendizagem Motora & Optativa 1, 2 e 3 \\
\cline { 2 - 4 } & Motricidade Humana & \\
\hline
\end{tabular}

Fonte: Projeto Pedagógico curso de Educação Física (UNIVERSIDADE FEDERAL DO PIAUÍ, 2009). 
Ratificando essa problemática, observou-se que a disciplina Higiene, Saúde e Meio Ambiente (única que apresenta o conteúdo Saúde Coletiva no seu Ementário - incluído em 2009) não teve o conteúdo expresso no plano de disciplina, fazendo-nos acreditar em uma não inserção/abordagem do assunto no processo de formação, fato que demonstra um retrocesso no currículo do curso, como pode ser observado nos fragmentos abaixo.

\section{Disciplina: Higiene, Saúde e Meio Ambiente}

Ementário: Saúde Pública e meio ambiente. Higiene individual e Coletiva. Saúde e Educação Física Escolar. Higiene do ambiente para as práticas esportivas. Efeitos nocivos das drogas à saúde. Doping. Saúde Mental. Estresse x atividade física. Efeitos climatológicos sobre o exercício físico. Esportes Ecológicos na Escola. Ambiente (UNIVERSIDADE FEDERAL DO PIAUÍ, 2009, p. 11).

Disciplina: Higiene, Saúde e Meio Ambiente Ementário: Higiene das instalações esportivas. Atividade física como profilaxia. Efeitos nocivos das drogas. Efeitos climatológicos sobre o exercício físico. Educação Ambiental. Ecologia. Saúde Mental: Estresse. (Plano de disciplina, 2013)

Tal realidade parece não ser um fato isolado no PPC da UFPI, pois Costa et al. (2012), ao avaliarem as grades curriculares de 61 graduações em EF, observaram que a maioria não abordava conteúdos referentes à Saúde Coletiva. E as IES, que possuem disciplinas específicas em seus currículos, o fazem predominantemente com abordagem curativa e prescritiva (ANJOS; DUARTE, 2009).

Neste contexto, destaca-se que o debate sobre o SUS é fundamental na formação acadêmica, devendo discutir e experimentar uma prática profissional pautada em seus princípios doutrinários (ROCHA; CENTURIÃO, 2007). É necessário considerar referenciais teóricos que alicercem 0 entendimento sobre a saúde também em sua base biopsicossocial, considerando os determinantes da saúde, como é o caso da obra A saúde em estado de Choque (MINAYO et al., 1986) e o artigo "Educação ou saúde? Educação x saúde? Educação e saúde" (COLLARES; MOYSES, 1985), que também foram suprimidos do plano de disciplina citado.

Apesar da existência, na formação básica, de disciplinas ligadas a ciências humanas e sociais, esses conteúdos parecem ainda muito desvalorizados na formação específica. Essa afirmação é reforçada pelo distanciamento da EF com a Saúde Coletiva, enquanto área específica da formação em saúde que considera em suas práticas os aspectos biopsicossociais, o fazer coletivo e as práticas comunitárias como ações essenciais de promoção de saúde. Com o referencial bibliográfico ligado ao PPC apresentando-se de forma geral predominantemente relacionado aos aspectos biológicos do exercício, treinamento/preparação, condicionamento e avaliação física, prevenção de doenças, aquisição de habilidades físico-desportivas, etc.

Evidencia-se um aporte teórico débil sobre os aspectos biopsicossociais, integralidade da atenção, humanização e técnicas relacionais de cuidado. Além disso, não se vê referência das políticas públicas de saúde no Brasil, como a de Promoção da Saúde (BRASIL, 2010), de Educação Popular em Saúde (BRASIL, 2013), de Atenção Básica (BRASIL, 2012) e das Leis Orgânicas da Saúde (BRASIL, 1990 a,b), que enfatizam os princípios e diretrizes do SUS. Tais conteúdos deveriam constituir o eixo estruturante da formação específica em saúde na EF, minimizando a distância existente entre as instituições de ensino e a formação de recursos humanos para a Saúde Coletiva/SUS.

A manutenção do enfoque biologicista reforça a formação para uma atuação que introjeta conceitos e valores ligados a uma visão de saúde individualista, que culpabiliza 0 
indivíduo por ter ou não saúde. Essa visão, tomada de forma exclusiva ou majoritária, direciona a aquisição de competências (prescrição, monitoramento e avaliação de atividades físicas) para intervir na modificação do estilo de vida das pessoas. Focando a área na prevenção de doenças, contribui para o processo de "patologização do sedentarismo", no qual o "remédio" é a prática de atividades físicas em doses e horários que precisão ser prescritos e monitorados (FERREIRA; CASTIEL; CARDOSO, 2012, FRAGA, 2006).

Em concordância com essas considerações Fraga, Carvalho e Gomes (2012) afirmam que os princípios do SUS ainda não encontram eco na atuação acadêmica e profissional na EF, fato presente mesmo diante da indicação legal que atribui ao SUS o ordenamento da formação dos profissionais de saúde. Ordenamento que tem sido incorporado às DCN e gerado modificações em quase todos os cursos, prevendo compromisso com a formação do profissional de saúde de forma alinhada ao sistema de saúde vigente no país, o SUS, discutindo aspectos como o trabalho em equipe e a atenção integral à saúde (CECCIM; FEUERWERKER, 2004).

Fraga, Carvalho e Gomes (2012) ratificam que o SUS não é sequer mencionado nas $\mathrm{DCN}$, fato que pode estar relacionado à baixa inserção dos profissionais de EF na rede de saúde e à falta de compreensão das demandas do SUS para a EF. Contudo, a inserção desses profissionais em programas como a Estratégia Saúde da Família, o NASF, os Centros de Apoio Psicossocial e, mais recentemente, os Polos de Academia da Saúde, indica a potencialidade deste profissional na articulação de práticas de cuidado de caráter multiprofissional, inspiradas no princípio da integralidade da atenção (FRAGA; CARVALHO; GOMES, 2012, p. 379), e coloca como urgente a incorporação desse alinhamento na formação.

Cabe ponderar afirmações das DCN que sinalizam competências profissionais na EF relacionadas à saúde - responsável pela prevenção, promoção, proteção e reabilitação da saúde (BRASIL, 2004). Contudo aparentemente, elas surgem como reserva de mercado, pois não refletiram alterações na intervenção/formação profissional (PASQUIM, 2010), como se observa na participação acanhada de profissionais da EF em colegiados de formulação de políticas públicas de saúde no Brasil, como os conselhos de saúde; nas principais reuniões científicas da saúde, como os congressos da Associação Brasileira de Saúde Coletiva e Associação Brasileira Rede Unida; bem como nos fóruns e instâncias deliberativos do setor, a citar as Conferências de Saúde (BAGRICHEVSKY et al., 2006).

Assim, concorda-se com Machado et al. (2007), quando afirmam que a formação em EF precisa de uma revisão curricular, a fim de incluir discussões que lhe são negligenciadas, ou mencionadas de forma tímida, como é o caso dos marcos conceituais da Saúde Coletiva, sobre os quais Bagrichevsky (2007) é mais específico, e sugere a necessidade da EF orientarse por uma releitura dos sentidos da saúde a partir de pressupostos e experiências produzidos e acumulados pela Saúde Coletiva. Esta fundada em marcos conceituais que privilegiam 0 cuidado integral ao ser humano (CARVALHO; CECCIM, 2006).

\section{POSSIBILIDADES DE APROXIMAÇÃO COM A FORMAÇÃO PARA A SAÚDE COLETIVA}

Diante do contexto apresentado, avanços teórico-metodológicos na formação para saúde na EF encontram curso em algumas iniciativas (Figura 4); mas, de modo geral, há poucas experiências que incluam espaço significativo que aborde a interação entre fazeres e 
saberes da cultura corporal na perspectiva de formação para o SUS (BAGRICHEVSKI, 2006), sendo insuficientes para efetivar uma formação qualificada para atuação em saúde. Porém, são passo importante para diminuir a lacuna entre a formação acadêmica e a realidade dos serviços de saúde pública.

Tais espaços, se presentes como caminhos teórico-metodológicos, poderiam ajudar na superação do paradigma medicalizador de saúde, circunstanciado ao corpo biológico, voltado ao mercado privado (academias, clubes, etc.), possibilitando um enfoque ampliado de saúde, em consonância com as necessidades da saúde coletiva e sintonizado com as necessidades sociais da população (BAGRICHEVSKI, 2006).

Figura 4 - Mapa conceitual dos resultados e discussões, referentes à categoria Possibilidades de Aproximação com a Formação para a Saúde Coletiva.

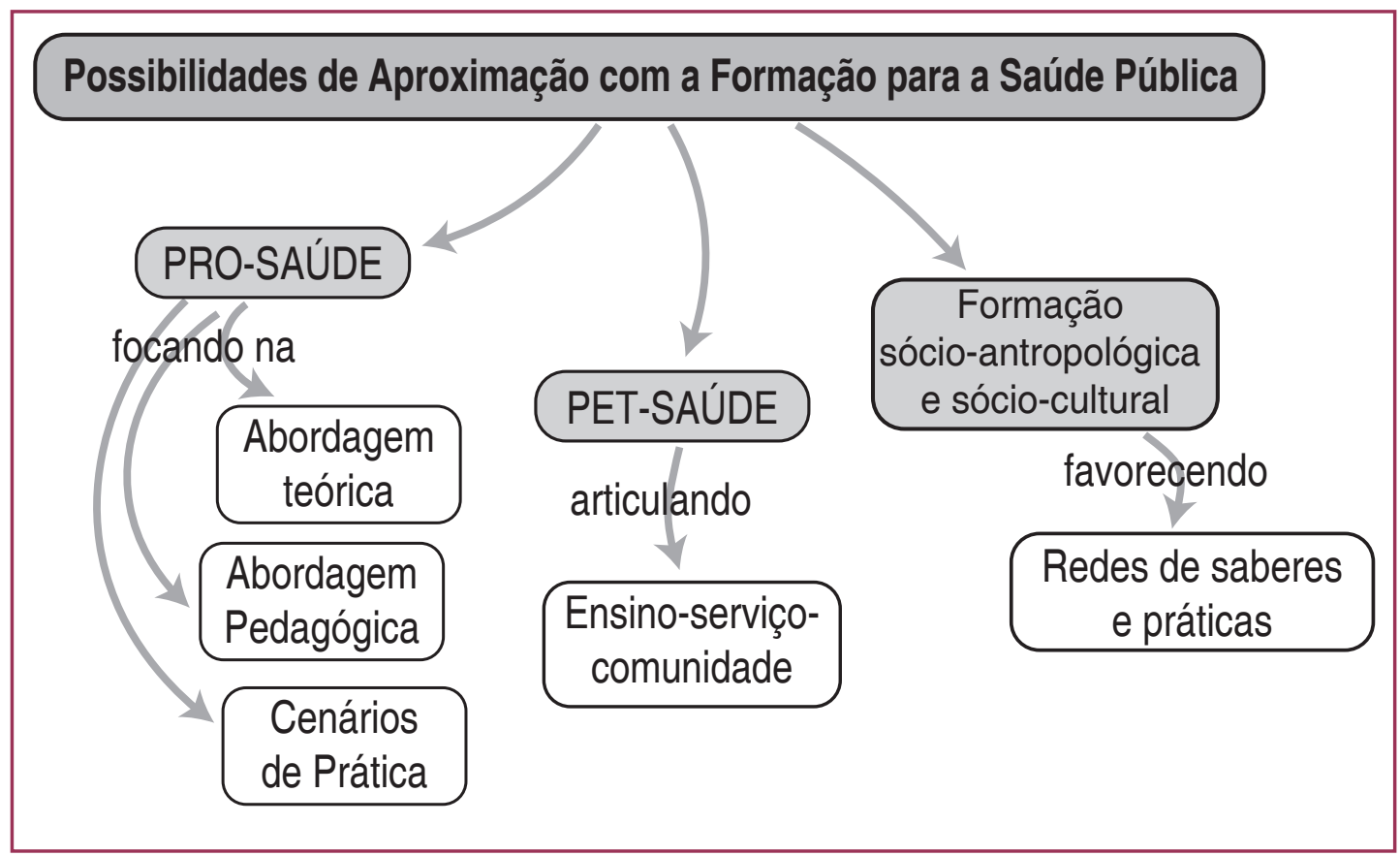

Fonte: Dados dos autores.

Destacamos como significantes e imprescindíveis as iniciativas do Ministério da Saúde e da Educação relacionadas ao Pró-Saúde e o PET-Saúde, que pretendem provocar transformações no processo de formação profissional, no sentido de corrigir o descompasso entre a orientação da formação dos profissionais de saúde e os princípios, as diretrizes e as necessidades do SUS.

Além da aproximação com o SUS, o Pró-Saúde centraliza-se no potencial pedagógico, no sentido de transpor o atual eixo da formação, centrado na atenção individualizada e pontual, para uma visão de atuação guiada pelas carências da população, baseada em um ser humano histórico, social e cultural. Desta forma, busca-se empoderar os futuros profissionais com relação aos determinantes do processo saúde-doença na comunidade e em todos os níveis do Sistema, conforme as diretrizes de universalização, equidade e integralidade, formando, assim, profissionais críticos e reflexivos, com conhecimentos, habilidades e atitudes que favoreçam sua atuação qualificada e integrada no SUS (BRASIL, 2007).

Alinhado ao Pró-Saúde, o PET-Saúde tem como pressuposto a educação pelo trabalho e a educação tutorial, e como fio condutor a integração ensino-serviço-comunidade, 
promovendo vivências em diversos cenários de práticas dos serviços de saúde pública aos acadêmicos, minimizando fragilidades dessas vivências. O Programa reflete os resultados das políticas públicas voltadas à formação ligadas à valorização da teoria para significação da prática. $E$, apesar de restrições relacionadas à abrangência numérica de graduandos atendidos, essas iniciativas já demonstram bons produtos na formação, percebendo-se um sutil movimento de incorporação de disciplinas, cenários de prática e estágios, no currículo do curso, que contemplem os serviços de saúde do SUS.

Acerca destas iniciativas, a UFPI desde 2005 aderiu ao Pró-Saúde, através do curso de odontologia (SOUSA NÉTTO et al., 2013) e em 2012 conseguiu a implantação do PETSaúde (UNIVERSIDADE FEDERAL DO PIAUÍ, 2012), tendo a EF se integrado timidamente ao Programa. Considerando que o PPC foi elaborado anteriormente à implantação do PETSaúde, não se observa menção do Programa no documento, não se percebendo também, no contexto atual, impactos do Pró-Saúde e PET-Saúde no PPC. Assim, espera-se que, em futura reformulação, tais programas façam parte dos documentos normativos do curso, a fim de que essas ações sejam mais bem institucionalizadas e tenham impacto sobre todo o coletivo do curso de EF da UFPI.

Destacam-se ainda iniciativas de professores de EF na constituição de redes de saberes e práticas comprometidas com uma formação sócio-antropológica e sociocultural que convirjam para a defesa e consolidação do SUS e para os desafios da formação em saúde. Como exemplo, temos grupos de pesquisa vinculados a programas de pós-graduação em EF, a citar a Universidade Federal do Rio Grande do Sul (Grupo Políticas de Formação em Educação Física e Saúde - Polifes), da Universidade de São Paulo (Grupo Educação Física \& Saúde Coletiva \& Filosofia) e da Universidade Federal do Espírito Santo (Grupo Laboratório de Estudo em Educação Física - Lesef) (FRAGA; CARVALHO; GOMES, 2012).

Tais grupos vêm construindo pesquisas com temáticas relacionadas ao currículo, ao processo ensino-aprendizagem e à formação para a saúde, pautando críticas ao modelo de atenção à saúde que tem repercutido na formação em $E F$, confrontando certos conteúdos e a pouca articulação com os serviços (FRAGA; CARVALHO; GOMES, 2012). Ressalta-se que são poucos os pesquisadores envolvidos em linhas de pesquisa com essas temáticas em pósgraduações em EF no Brasil, o que obstaculiza a tarefa de pensar as políticas de formação da área alinhada à Saúde Coletiva (FRAGA; CARVALHO; GOMES, 2012).

No contexto da UFPI, o Núcleo de Estudos em Saúde Pública (NESP) do Centro de Ciências da Saúde (CCS) destaca-se na Saúde Coletiva e fortalecimento do SUS (UNIVERSIDADE FEDERAL DO PIAUÍ, 2016). Criado em 1990, o núcleo, formado por docentes, discentes e técnicos de diferentes áreas, não conta com nenhum representante do curso de EF.

Uma maior aproximação do curso de EF com o NESP seria importante para potencializar as competências apontadas no próprio PPC: "desenvolver, participar e aplicar pesquisas e/ou outras formas de produção de conhecimento que objetivem a qualificação da prática profissional", as quais precisam estar embasadas, entre outras, por competências relacionadas a "promoção, prevenção e reabilitação à saúde, dando atenção integral à saúde dos indivíduos, das famílias e das comunidades" (UNIVERSIDADE FEDERAL DO PIAUÍ, 2009, p. 20). 


\section{CONSIDERAÇÕES FINAIS}

Os documentos normativos da EF aqui analisados indicaram importante influência histórica de uma concepção reducionista de saúde de base higienista, considerando predominantemente o componente biológico na relação do exercício físico com a saúde, em estreita relação com a concepção do modelo biomédico, para a formação nas profissões em saúde. Destacam-se limitações de uma proposta formativa que favoreça uma compreensão da realidade concreta do trabalho na perspectiva mais ampliada de saúde, que considere sua determinação social, marca da atual política pública de saúde.

Em um modelo disciplinar de formação, as disciplinas específicas parecem não ter densidade suficiente para produzir superações do enfoque teórico-metodológico hegemônico de saúde para um enfoque ampliado, em consonância com as necessidades do SUS. Não foi identificada sequer uma disciplina relacionada à discussão da Saúde Coletiva, o que no citado modelo de formação seria condição mínima, considerando as competências previstas para o futuro profissional de EF, de acordo com as DCN e PPC.

Como área fundada em marcos conceituais relacionados ao cuidado integral ao ser humano, uma disciplina de Saúde Coletiva, como estratégia inicial, poderia incorporar à bibliografia básica referências atualizadas e leituras relativas às politicas públicas de saúde, a fim de contribuir para o desenvolvimento de uma perspectiva mais integral da saúde além de possibilitar aproximações com propostas teórico-metodológicas de bases sócio-antropológicas e socioculturais.

Diante do exposto, torna-se imprescindível uma reformulação nas $\mathrm{DCN}$ e reestruturação curricular do curso de EF da UFPI, no sentido de orientar uma formação que contemple minimamente aspectos relacionados à Saúde em um contexto mais amplo e ao SUS enquanto modelo de atenção à Saúde.

E, para além disso, há a necessidade urgente e emergente de um maior envolvimento e comprometimento da área em questões sociais e políticas que garantam intervenções pautadas nas necessidades do sistema de saúde e da população brasileira, bem como na construção de competências técnicas, éticas e políticas para o enfrentamento das desigualdades e na luta pela garantia dos direito à saúde no país.

\section{REFERÊNCIAS}

AMARAL, Gislene Alves et al. Formação profissional e diretrizes curriculares da educação física. Revista Especial de Educação Física, Uberlândia, v. 3, n. 1, p. 27-40, 2006.

ANJOS, Tatiana Coletto; DUARTE, Ana Cláudia Garcia de Oliveira. A educação física e a estratégia de saúde da família: formação e atuação profissional. Physis, Rio de Janeiro, v. 19, n. 4, p. 11271144, 2009.

BAGRICHEVSKY Marcos. A formação profissional em Educação Física enseja perspectivas (críticas) para atuação na saúde coletiva? In: FRAGA, Alex Branco; WACHS, Felipe (Org.). Educação física e saúde coletiva: políticas de formação e perspectivas de intervenção. Porto Alegre: Editora da UFRGS, 2007. p. 33-46.

BAGRICHEVSKY, Marcos; ESTEVÃO, Adrian; PALMA, Alexandre. Saúde coletiva e educação física: aproximando campos, garimpando sentidos. In: BAGRICHEVSKY, Marcos (Org.). A saúde em debate na educação física. Blumenau: Nova Letra, 2006. v. 2, p. 21-44. 
BARBOSA-RINALDI, leda Parra. Formação inicial em Educação Física: uma nova epistemologia da prática docente. Movimento, Porto Alegre, v. 14, n. 3, p. 185-207, 2008.

BARDIN, Laurence. Análise de conteúdo. São Paulo: Edições 70, 2011.

BELTRÃO, Ricardo Ernesto Vasque; NOGUEIRA, Fernando do Amaral Nogueira. A pesquisa documental nos estudos recentes em administração pública e gestão social no Brasil. In: ENCONTRO DA ANPAD, 35., 2011, Rio de Janeiro. Anais... Disponível em: <http://www.anpad.org.br/admin/pdf/ EPQ2700.pdf>. Acesso em: 4 abr. 2016.

BRACHT, Valter. A constituição das teorias pedagógicas da Educação Física. Caderno Cedes, Campinas/SP, v. 19, n. 48, p. 69-88, 1999.

BRASIL. (Constituição, 1988). Constituição da República Federativa do Brasil. Brasília, Senado Federal, 1988.

BRASIL. Lei $n^{\circ} \mathbf{8 0 8 0}$, de 19 de setembro de 1990a. Dispõe sobre as condições para a promoção, proteção e recuperação da saúde, a organização e o funcionamento dos serviços correspondentes e dá outras providências. Disponível em: <http://www.planalto.gov.br/ccivil 03/leis/L8080.htm>. Acesso em: 4 abr. 2016.

BRASIL. Lei 8142, de 28 de dezembro de 1990b. Dispõe sobre a participação da comunidade na gestão do Sistema Único de Saúde (SUS) e sobre as transferências intergovernamentais de recursos financeiros na área da saúde e dá outras providências. Disponível em: <http://www.planalto.gov.br/ ccivil 03/leis/L8142.htm>. Acesso em: 4 abr. 2016.

BRASIL. Programa Nacional de Reorientação da Formação Profissional em Saúde - Pró-Saúde: objetivos, implementação e desenvolvimento potencial. Brasília: Ministério da Saúde, 2007.

BRASIL. Resolução n 7, de 31 de março de 2004. Institui as Diretrizes Curriculares Nacionais do Curso de Graduação em Educação Física. Diário Oficial da União, Brasília, 5 abr. 2004.

BRASIL. Resolução n 218, de 06 de março de 1997. Reconhece os profissionais da área da saúde. Diário Oficial da União, Brasília, 5 maio 1997.

BRASIL. Ministério da Saúde. Portaria no 2.761, de 19 de novembro de 2013. Institui a Política Nacional de Educação Popular em Saúde no âmbito do Sistema Único de Saúde (PNEPS-SUS). Disponível em: <http://bvsms.saude.gov.br/bvs/saudelegis/gm/2013/prt2761 1911 2013.html>. Acesso em: 4 abr. 2016.

BRASIL. Ministério da Saúde. Política nacional de atenção básica. Brasília: Ministério da Saúde, 2012.

BRASIL. Ministério da Saúde. Secretaria de Vigilância em Saúde. Secretaria de Atenção à Saúde. Política nacional de promoção da saúde. 3. ed. Brasília : Ministério da Saúde, 2010.

BRUGNEROTTO, Fábio Augusto. Caracterização dos currículos de formação profissional em educação física: um enfoque sobre saúde. 2008. Dissertação (Mestrado em Educação Física) Faculdade de Ciências da Saúde, Universidade Metodista de Piracicaba, Piracicaba, 2008. Disponível em: <https://www.unimep.br/phpg/bibdig/pdfs/2006/DXGRUMASKXPK.pdf>. Acesso em: 4 abr. 2016.

CARVALHO, Yara Maria. Entre o biológico e o social: tensões no debate teórico acerca da saúde na educação física. Motrivivência, Florianópolis, n. 24, p. 97-105, 2005.

CARVALHO, Yara Maria; CECCIM, Ricardo. Formação e educação em saúde: aprendizagens com a saúde coletiva. In: CAMPOS, Gastão Wagner dos Santos (Org.). Tratado de saúde coletiva. 2. ed. São Paulo: Hucitec-Fiocruz, 2006. p. 149-182.

CECCIM, Ricardo Burg; FEUERWERKER, Laura Macruz. Mudança na graduação das profissões de saúde sob o eixo da integralidade. Cadernos de Saúde Pública, Rio de Janeiro, v. 20, n. 5, p. 14001410,2004 
CECCIM, Ricardo; BILIBIO, Luiz Fernando. Singularidades da Educação Física na saúde: desafios à educação de seus profissionais e ao matriciamento interprofissional. In: FRAGA, Alex Branco; WACHS, Felipe (Org.). Educação física e saúde coletiva: políticas de formação e perspectivas de intervenção. Porto Alegre: Editora da UFRGS, 2007. p. 47-62.

CERVO, Amado Luiz; BERVIAN, Pedro Alcino; SILVA, Roberto. Metodologia científica. 6. ed. São Paulo: Pearson Prentice Hall, 2010.

COLLARES, Cecília Azevedo Lima; MOYSÉS, Maria Aparecida Affonso. Educação ou saúde? Educação X saúde? Educação e saúde! Cadernos Cedes, São Paulo, n. 15, p.7-16, 1985.

COSTA, Larissa Chaves et al. Formação profissional e produtividade em saúde coletiva do profissional de Educação Física. Revista Brasileira de Atividade Física e Saúde, Pelotas, v. 17, n. 2, p. 107-13, 2012.

FALCI, Denise Mourão; BELISARIO, Soraya Almeida. A inserção do profissional de Educação Física na atenção primária à saúde e os desafios em sua formação. Interface, Botucatu, v. 17, n. 47, p. 885899, 2013.

FERREIRA, Marcos Santos; CASTIEL, Luis David; CARDOSO, Maria Helena Cabral. A patologização do sedentarismo. Saúde e Sociedade, São Paulo, v. 21, n. 4, p. 836-847, 2012.

FRAGA, Alex Branco. Exercício da informação: governo dos corpos no mercado da vida ativa. Campinas: Autores Associados, 2006.

FRAGA, Alex Branco; CARVALHO, Yara Maria; GOMES, Ivan Marcelo. Políticas de formação em educação física e saúde coletiva. Trabalho, Educação e Saúde, Rio de Janeiro, v. 10, n. 3, p. 367386, 2012.

GIL, Antônio Carlos. Como elaborar projetos de pesquisa. 4. ed. São Paulo: Atlas, 2009.

LAMPERT, Jadete Barbosa. Tendências de mudanças na formação médica no Brasil. 2002. Tese (Doutorado em Saúde Pública) - Escola Nacional de Saúde Pública, Fundação Oswaldo Cruz, Rio de Janeiro, 2002. Disponível em: <http://arca.icict.fiocruz.br/bitstream/icict/4369/2/135.pdf >. Acesso em: Acesso em: 4 abr. 2016.

LEMOS, Maria Lovane et al. As contradições do processo de elaboração das diretrizes curriculares nacionais dos cursos de formação em Educação Física e os movimentos de resistência à submissão ao mercado. Movimento, Porto Alegre, v. 18, n. 3, p. 27-49, 2012.

LIBÂNEO, José Carlos. Organização e gestão da escola: teoria e prática. 5. ed. Goiânia: Alternativa, 2004.

LIMA, Gercina Ângela Borém. Mapa Conceitual como ferramenta para organização do conhecimento em sistema de hipertextos e seus aspectos cognitivos. Perspectivas em Ciência da Informação, Belo Horizonte, v. 9, n. 2, p. 134-145, 2004.

LOCH, Mathias Roberto et al. A saúde pública nos anais do Congresso Brasileiro de Atividade Física e Saúde (1997-2009): revisão sistemática. Revista Brasileira de Atividade Física \& Saúde, Pelotas, v. 16, n. 2, p. 162-167, 2011.

LUZ, Madel. Novos saberes e práticas em saúde coletiva: estudo sobre racionalidades médicas e atividades corporais. 3. ed. São Paulo: Hucitec, 2007.

MACHADO, Maria de Fátima Antero Sousa et al. Integralidade, formação de saúde, educação em saúde e as propostas do SUS: uma revisão conceitual. Revista Ciência \& Saúde Coletiva, Rio de Janeiro, v. 12, n. 2, p. 335-342, 2007.

MARCONI, Marina de Andrade; LAKATOS, Eva Maria. Fundamentos de metodologia científica. 7. ed. São Paulo: Atlas, 2010. 
MELLO, Ana Lúcia Schaefer Ferreira; MOYSES, Simone Tetu; MOYSES, Samuel Jorge. A universidade promotora de saúde e as mudanças na formação profissional. Interface, Botucatu, v. 14, n. 34, p. 683-692, 2010.

MINAYO Maria Cecília Souza. Pesquisa social: teoria, método e criatividade. 28. ed. Petrópolis: Vozes, 2009.

MINAYO, Maria Cecílio Souza et al. A saúde em estado de choque. Rio de Janeiro: Federação de Órgãos para Assistência Social e Educacional, 1986.

PALMA, Alexandre. A educação continuada do professor de educação física: possibilitando práticas reflexivas. 2001. Tese (Doutorado em Educação Física) - Faculdade de Educação Física, Universidade Estadual de Campinas, Campinas, 2001. Disponível em: <http://www.bibliotecadigital. unicamp.br/document/?code=vtls000235778>. Acesso em: Acesso em: 4 abr. 2016.

PASQUIM, Heitor Martins. A saúde coletiva nos cursos de graduação em Educação Física. Saúde e Sociedade, São Paulo, v. 19, n. 1, p. 93-200, 2010.

ROCHA, Vera Maria; CENTURIÃO, Carla Haas. Profissionais da saúde: formação, competência e responsabilidade social. In: FRAGA, Alex Branco; WACHS, Felipe (Org.). Educação Física e saúde coletiva: políticas de formação e perspectivas de intervenção. Porto Alegre: Editora da UFRGS, 2007. p. 17-32.

SOUSA NÉTTO, Otacílio Batista et al. O pró-saúde no curso de odontologia da Universidade Federal do Piauí (UFPI): relato de uma vivência de cinco anos. Ciênc., Cuid. Saúde. Revista Ciência \& Saúde Coletiva, Rio de Janeiro, v. 12, n. 2, p. 391-397, 2013.

TAFFAREL, Celi Neuza Zulke. Critica a formação na Educação Física: Em defesa de novas diretrizes curriculares. 2012. Rascunho digital. FACED/UFBA. Salvador/BA . disponível em: <http:// www.rascunhodigital.faced.ufba.br/ver.php?idtexto=898>. Acesso em: 4 abr. 2016.

TRIVIÑOS, Augusto Nibaldo Silva. Introdução à pesquisa em Ciências Sociais: a pesquisa qualitativa em educação. São Paulo: Atlas, 1987.

UNIVERSIDADE FEDERAL DO PIAUÍ. Departamento de Educação Física. Projeto pedagógico curso de licenciatura plena em Educação Física. Teresina, 2009. Disponível em: <http://leg.ufpi.br/ subsiteFiles/cc/arquivos/files/Educa\%C3\%A7\%C3\%A30\%20F\%C3\%ADsica\%202012.pdf>. Acesso em: 4 abr. 2016.

UNIVERSIDADE FEDERAL DO PIAUÍ. Núcleo de Estudos em Saúde Pública. Educação e Saúde: bases epistemológicas e metodológicas da formação de profissionais para o Sistema Único de Saúde. Teresina: Universidade Federal do Piauí, 2010.

UNIVERSIDADE FEDERAL DO PIAUÍ. Núcleo de Estudos em Saúde Pública. Aprovado Projeto PRÓ-SAÚDE/ PET-SAÚDE UFPI. 2012. Disponível em: <http://www.leg.ufpi.br/nesp/materias/index/ mostrar/id/6911>. Acesso em: 4 abr. 2016.

UNIVERSIDADE FEDERAL DO PIAUÍ. Núcleo de Estudos em Saúde Pública. Núcleos relacionados. 2016. Disponível em: <http://www.ufpi.br/pesquisa/nucleos-relacionados >. Acesso em: 4 abr. 2016. 
